\title{
Common defects in injection molding of plastic products and their influence on product quality
}

Tomasz CHACIŃSKI, Paweł SUTOWSKI

DOI: $10.30464 /$ jmee.2021.5.1.7

Cite this article as:

Chaciński T., Sutowski P. Common defects in injection molding of plastic products and their influence on product quality. Journal of Mechanical and Energy Engineering, Vol. 5(45), No. 1, 2021, pp. 7-14.

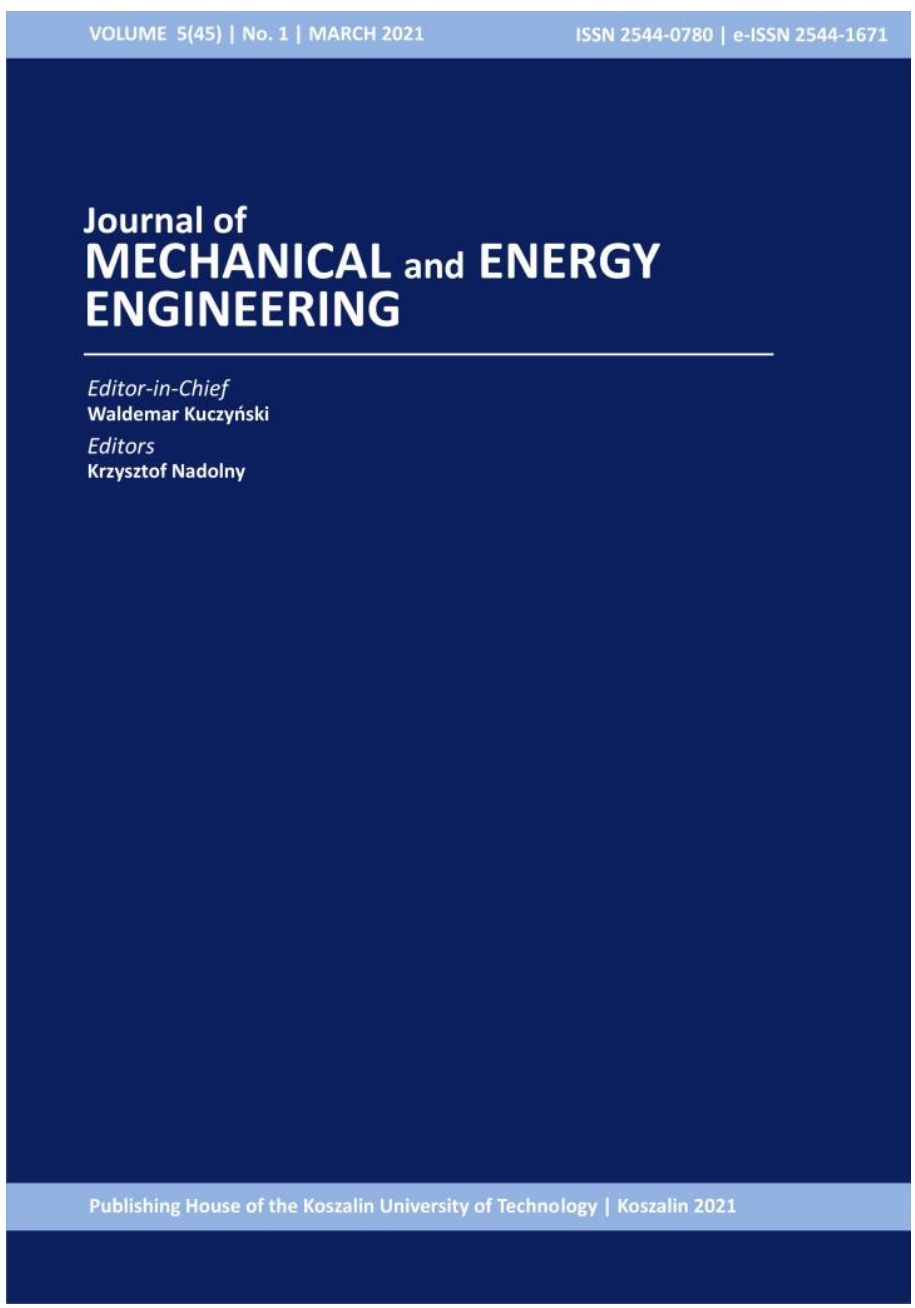

Journal of Mechanical and Energy
Engineering

Website: jmee.tu.koszalin.pl

ISSN (Print): 2544-0780

ISSN (Online): 2544-1671

Volume: 5(45)

Number: 1

Year: 2021

Pages: 7-14

Article Info:

Received 16 February 2021

Accepted 2 March 2021

\section{Open Access}

This article is distributed under the terms of the Creative Commons Attribution 4.0 (CC BY 4.0) International License (http://creativecommons.org/licenses/by/4.0/), which permits unrestricted use, distribution, and reproduction in any medium, provided you give appropriate credit to the original author(s) and the source, provide a link to the Creative Commons license, and indicate if changes were made. 


\title{
COMMON DEFECTS IN INJECTION MOLDING OF PLASTIC PRODUCTS AND THEIR INFLUENCE ON PRODUCT QUALITY
}

\author{
Tomasz CHACIŃSKI ${ }^{*}$, Paweł SUTOWSKI ${ }^{2}$ \\ ${ }^{1 *}$ Faculty of Mechanical Engineering, Department of Production Engineering, Koszalin University \\ of Technology, Raclawicka 15-17, 75-620 Koszalin, Poland, e-mail: tomasz.chacinski@tu.koszalin.pl \\ ${ }^{2}$ Faculty of Mechanical Engineering, Department of Production Engineering, Koszalin University \\ of Technology, Raclawicka 15-17, 75-620 Koszalin, Poland
}

(Received 16 February 2021, Accepted 2 March 2021)

\begin{abstract}
The article deals with issues related to quality management and quality assessment in production of plastic articles in injection moulding. Expert knowledge collected in textbooks and literature allows to get acquainted with the characteristics of plastic article production and product quality defects arising in such processes. The characteristics and technology of plastics processing are discussed, the most frequent quality defects occurring in the production of articles made of plastics by injection molding are listed. On the basis of expert knowledge collected in the literature, a series of actions leading to the elimination of each of the mentioned quality defects has also been proposed.
\end{abstract}

Keywords: injection molding, plastic articles, quality in injection molding, defects in plastic articles

\section{INTRODUCTION}

Plastic articles have become an important and integral part of modern life. Plastics are used to make articles, parts and machines that we use every day. The clothes we wear, the cars we drive, the devices we use to communicate with each other, the containers we use to store food or objects - all these things are partly or entirely made of plastics. Plastics owe their popularity to their low manufacturing costs compared to the materials they replace (wood, ceramics, metals). Plastics are also characterized by the fact that they can be given properties that are not available for other materials (color, flexibility, hardness, nonflammability, odorless). The advantages of this material are therefore the ease of processing, recovery and the wide spectrum of applications [13].

Quality of product is one of the critical measures of production evaluation. Introducing faulty products on the market, which do not meet quality standards, may have serious consequences for the company's image and consumer safety. Therefore, it is an important issue of the production management field, and its beginning is at the stage of product design as part of production preparation. Quality is defined as a set of product features, which aim to satisfy the customer to the assumed extent, and together with other product features, it affects the competitiveness of the product. However, it is rare to achieve the quality of the product compliant with the design assumptions, therefore the permissible deviations are determined, which allow to state the compliance of the product with the accepted quality standards [8].

Quality features of a product within the quality dimensions can be divided due to the possibility of their measurement into [7]:

1. Measurable (numerical) - the result of the measurement can be expressed numerically by a specific unit of measurement. There is a distinction between continuous and discrete measurable characteristics. Continuous measurable characteristics are those whose measurement is limited by the resolution of the measurement method. Discrete measurable characteristics are those whose measurement allows to express a finite number of states.

2. Non-measurable (alternative) - they cannot be measured or expressed numerically. Such qualitative characteristics, on the other hand, can be observed and studied, and they are expressed descriptively. 
Defining quality in the area of industrial manufacturing in a simple and systematic way may prove to be a challenge due to the labile nature of this concept. Undertaking the quality assurance of a product must take into account many factors which are guided by a potential buyer. The manufacturer should ensure the competitiveness of the product, meet the quality requirements imposed at the design stage and the requirements set out in the law on safe operation, ensure reliability (to increase user satisfaction, but also to reduce servicing costs), and ultimately - meet customer expectations [11].

\section{PRODUCTION OF PLASTIC ARTICLES}

This chapter deals with the production of plastic articles and describes the technology of manufacturing.

\subsection{Common methods of plastic articles producion}

Table 1 summarizes selected plastic processing methods and examples of products manufactured by each method [2].

Tab. 1. Summary of selected plastic processing methods and example products [2]

\begin{tabular}{ccc}
\hline Processing method & $\begin{array}{c}\text { Common } \\
\text { materials used }\end{array}$ & Example products \\
\hline Extrusion & PE, PP, PVC & $\begin{array}{c}\text { Profiles, filaments, } \\
\text { tubes, cable sheaths }\end{array}$ \\
\hline Blow moulding & $\begin{array}{c}\text { LDPE, PP, } \\
\text { PET, PVC, } \\
\text { HDPE }\end{array}$ & Bottles \\
& ABS, HDPE, & Tapes, films and \\
balendering & PP, PS & boards \\
\hline Injection moulding & $\begin{array}{c}\text { PC, PVC, POM, } \\
\text { PMMA, PS, } \\
\text { PSEI, }\end{array}$ & $\begin{array}{c}\text { Containers, buckets, } \\
\text { vessels, housings, } \\
\text { gears }\end{array}$ \\
\hline Rotomoulding & $\begin{array}{c}\text { LLDPE, HDPE, Large tanks, buckets, } \\
\text { drums }\end{array}$ \\
\hline
\end{tabular}

\subsection{Extrusion}

Extrusion usually takes place on machines (Fig. 2) equipped with a feeder, screw system and extrusion nozzle. Feedback heater systems are used for precise temperature control. The screw system is usually divided into three zones; the feed zone, where material is loaded into the screw system; the transition zone, where material is plasticized; and the melt-conveying zone, where polymer is driven into the extruder. The shape of the nozzle opening determines the final crosssectional geometry of the extruded material [10].

\subsection{Blow moulding}

Blow moulding is the forming of a hollow object (such as bottles) by blowing a thermoplastic molten tube called a "parison" in the shape of a mold cavity. The process consists of extruding a parison on which female mold halves are closed (Fig. 1). The mold halves contain the shape of the product. The bottom opening of the parison is pinched shut by the closing female mold halves. A pressurized gas (usually air) is introduced into the parison through blow pin blowing the heated parison out against the cavity walls to form the product [1].
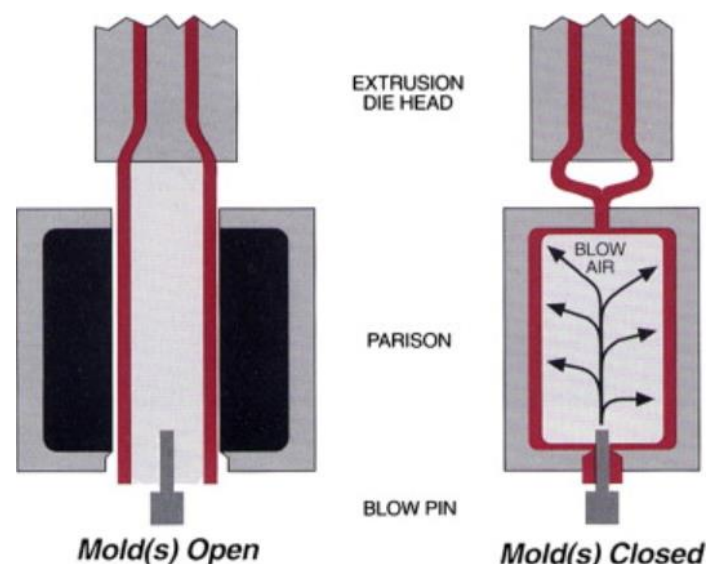

Mold(s) Closed

Fig. 1. The blow molding cycle [1]

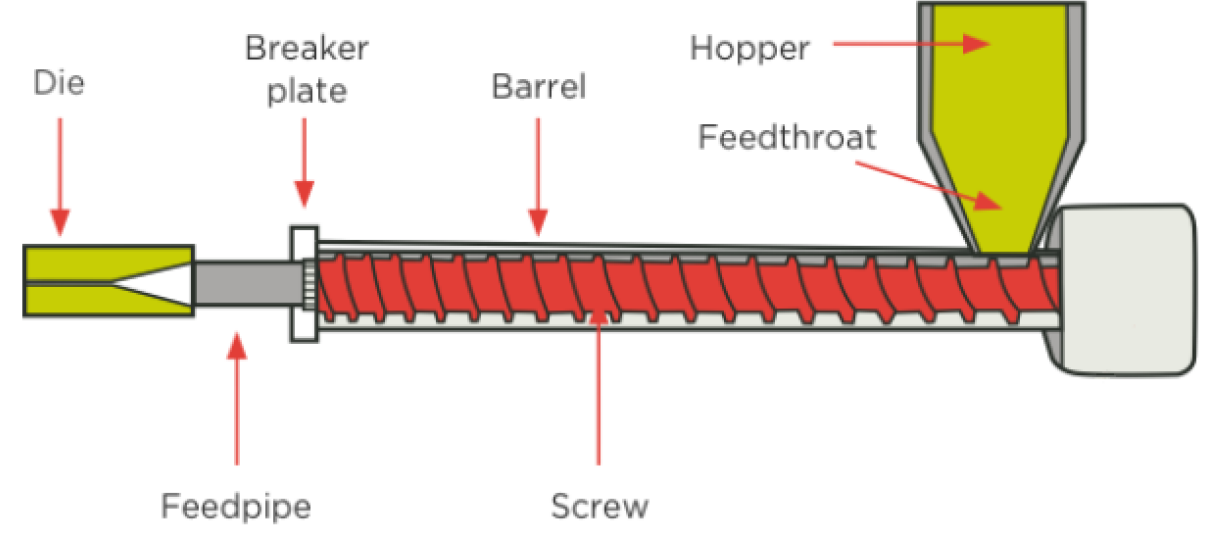

Fig. 2. Overview of a plastic extrusion machine [23] 


\subsection{Calendering}

Calendering plastics is a process that is used in many industries to produce rolled sheets of precise thickness and appearance (Fig. 3). Calendering of molten polymers is a continuous sheet or film production process that is done by passing materials through sets of heated, counter-rotating rolls [12].

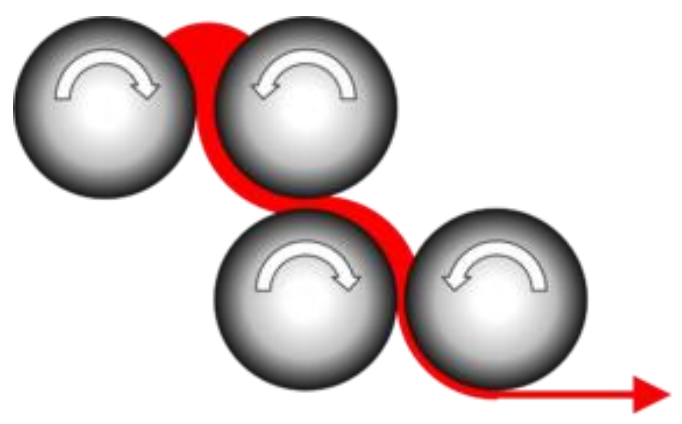

Fig. 3. Calendering process [16]

\subsection{Injection molding method}

Injection molding is a major processing technique for converting thermoplastic and thermosetting materials, consuming worldwide approximately $32 \%$ of all plastics [9].The injection molding process is done on injection molding machines (Fig. 4). It is considered the dominant process in plastics processing. The process is carried out in cycles and consists of plasticizing, melting and mixing the plastic, followed by injection into an injection mold. Figure 5 shows schematics of injection molding machine.

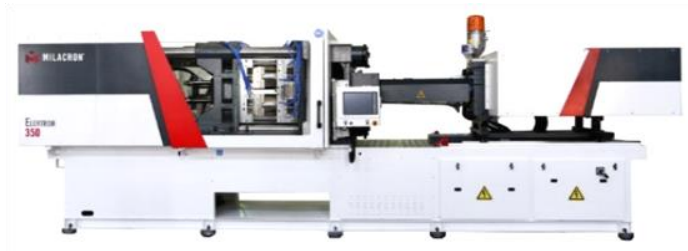

Fig. 4. Milacron's Electron Series electric injection molding machine [21]

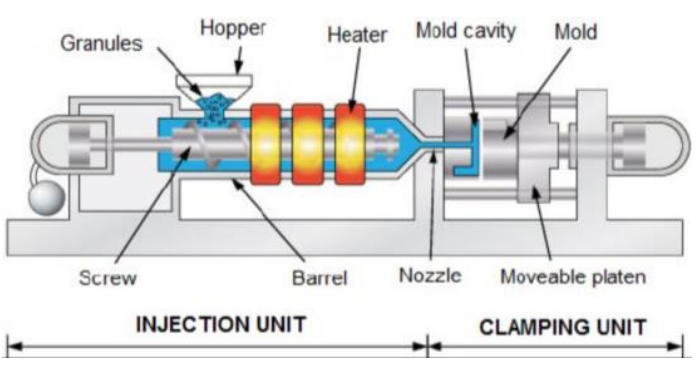

Fig. 5. Simple schematic of injection molding machine [14]

Injection molding machines consist of a plasticizing system (similar to those in extruders), a drive system, and a tool system. Below are described the following phases of the injection molding process [5]:

1. Mold closing - this is the phase in which the tool is closed. This is accomplished by rapidly advancing the moving part of the mold.

2. Injection-during this phase the injection system is moved against the tool. The nozzle is brought into contact with the tool sleeve. By rotation of the screw in the plasticizing system the liquid material is injected into the tool.

3. Pressing - the screw in the plasticizing system is pressed against the nozzle, which causes the filling of plastic into the tool seat. This phase is necessary because of the resulting lack of plastic volume. The volume of plastic pressed into the mold decreases as a result of shrinkage of the plastic.

4. Plasticization - a rotary screw movement takes place. As a result, the plastic is taken from the feeder. The screw moves to the initial position. During its movement, the material taken from the screw is subjected to temperature in order to plasticize, mix and compress it (compression of plastic takes place due to the shape of the screw).

5. Opening - during this phase, the closing pressure of the fixed and moving mold parts decreases. The mold is opened and the part is ejected from the tool. Ejection from the tool is usually carried out by means of ejector pins integrated in the tool.

In their study, Garbacz and Sikora [5] list the following factors that are important to the injection molding process:

- temperature of the heating zones of the plasticizing system,

- temperature of the injection nozzle,

- mould temperature,

- injection pressure,

- clamping pressure,

- mould closing force,

- screw speed,

- screw stroke,

- cycle time and time of each cycle phase,

- injection speed.

\subsection{Rotomoulding}

Rotational molding (also called rotomolding) is the process of making large, hollow objects out of plastic. It is characterized by the fact that the resulting products have no seams. The parts produced have a wide range of applications (from tanks to containers or furniture). Rotomoulding is done by heating a thin-walled mould which contains a polymer powder (Fig. 6). During heating, the mold rotates multiaxially. The material inside heats up, melts and coats the inside walls of the mold. Then the mold is cooled, allowing the product to solidify. The part is removed and the mold is loaded for the next cycle [4]. 


\section{QUALITY AND DEFECTS OF PLASTIC ARTICLES IN INJECTION MOLDING}

As with all manufacturing methods, quality defects can occur during the injection molding process causing deficiencies or unsatisfactory part properties. Selected quality defects of molded parts occurring during injection molding are described.
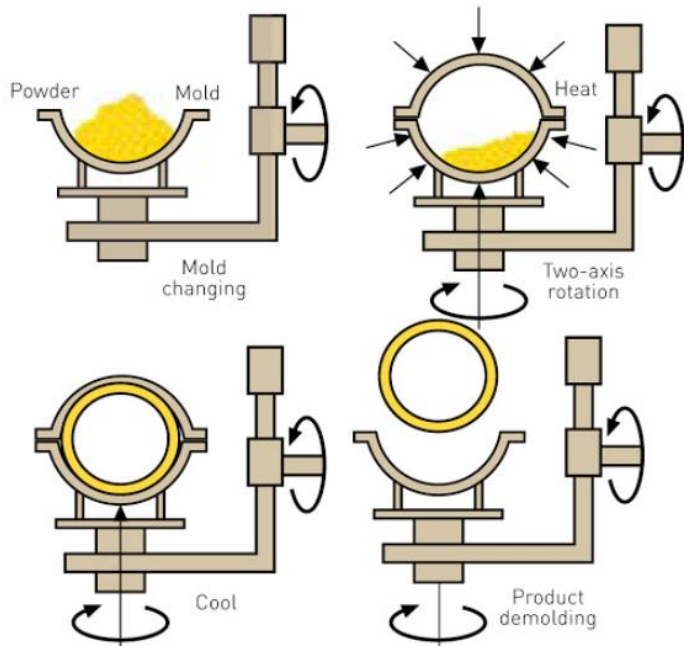

Fig. 6. Rotational molding process [24]

\subsection{Inclusions}

Those are the dark spots visible on the surface of a molded part (Fig. 7). The cause of inclusions is usually contamination of the raw material (granulate) or its degradation [6].

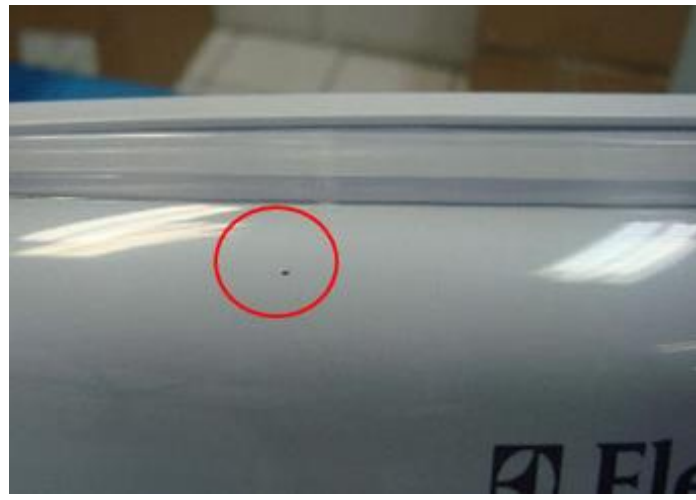

Fig. 7. Inclusions on the surface of molded parts [15] [6]:

The actions to be taken to eliminate this defect are

- reduce the temperature in the plasticizing unit,

- reduce the injection speed and pressure,

- clean the machine,

- check the plastic contamination.

\subsection{Brittleness/breakage and weld marks}

The tendency of the molded part to excessive cracking and crumbling at low pressure or impact is most often caused by degradation of the raw material during the process. The moldings also crack at the plastic welding points (Fig. 8), where micro-cracks lead to weakening of the structure [6].

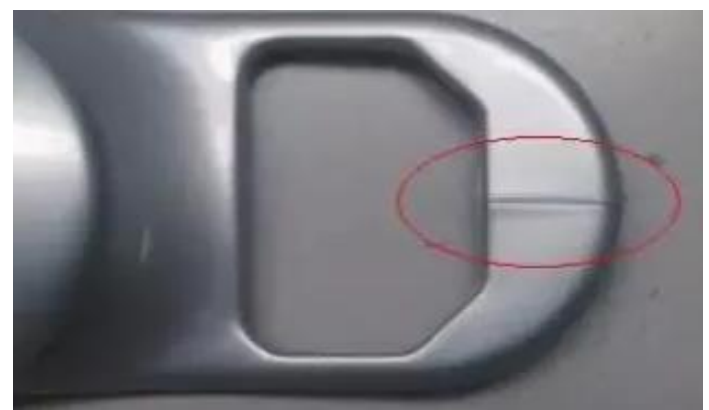

Fig. 8. Weld marks on molded part [18]

Actions that can be taken to eliminate this molding defect are [6]:

- reduce the temperature in the plasticizing unit,

- check contamination of the raw material,

- check moisture content of the raw material,

- reduce the proportion of regranulate in the mix.

\subsection{Gassings}

Gassings (Fig. 9) occur due to improper mold ventilation and gas entrapment at the time of plastic injection [6].

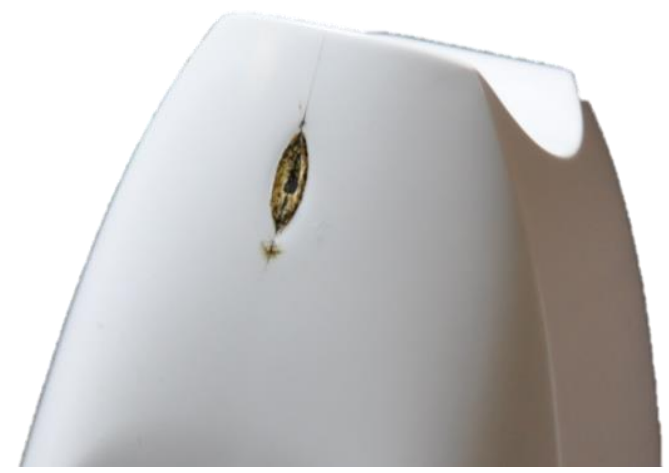

Fig. 9. Gassings in the injection molding process [17]

In order to eliminate the problem of outgassing, it is necessary to [6]:

- introduce structural changes in the mould in order to change the polymer flow or use a different injection point,

- change the location of the injection point,

- adjust the wall thickness.

\subsection{Discoloration}

Discoloration or streaks are usually caused by uneven dye dosage at the plasticization stage (Fig. 10). They can also be a result of incompatibility of the polymer with additives used [6]. 


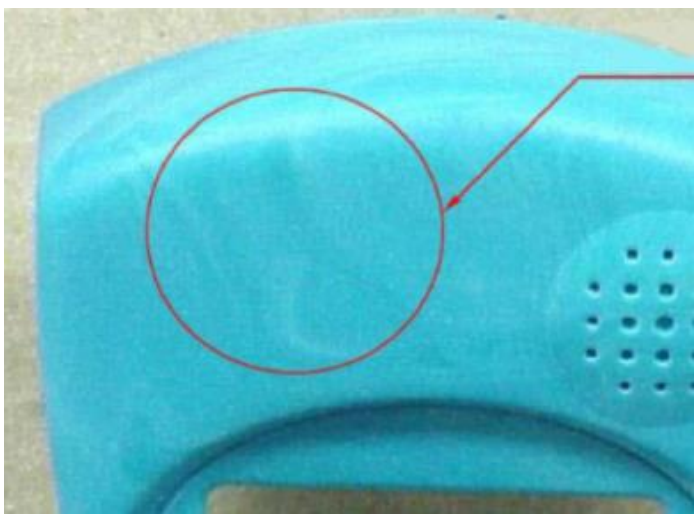

Fig. 10. Discoloration on molded part [22]

In order to eliminate the problem of discoloration and streaking, it is necessary to [6]:

- check the compatibility of the polymer with the additives used,

- check the screw and screw housing for damage,

- increase the injection speed,

- change the screw rotation speed parameter,

- check the temperature of the plasticizing process,

- increase the pressure during the plasticizing process.

\subsection{Ejector pin marks}

Ejector pin marks occur as visible dots, a pinshaped difference in surface gloss (Fig. 11), or white marks caused by material stress [6].

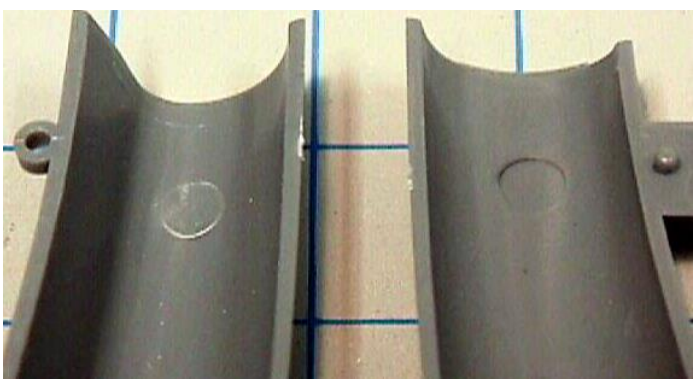

Fig. 11. Ejector pin marks in the form of a point difference in surface of a molded part [20]

To solve the problem of ejector pin marks appearing, you can [6]:

- make sure that the ejector pins are finished smooth with the inner surface of the mold,

- increase cooling time,

- reduce the reheating temperature of the mold,

- reduce the temperature of the plasticizing process,

- install additional ejector pins or increase the diameter of those present.

\subsection{Flashes}

Flash (Fig. 12) occurs when the material flows out of the mold pocket during the injection process. The problem usually occurs with low viscosity plastics. It is a common problem with first production runs on a new tool (mold) when the mold surfaces have not yet aligned [6].

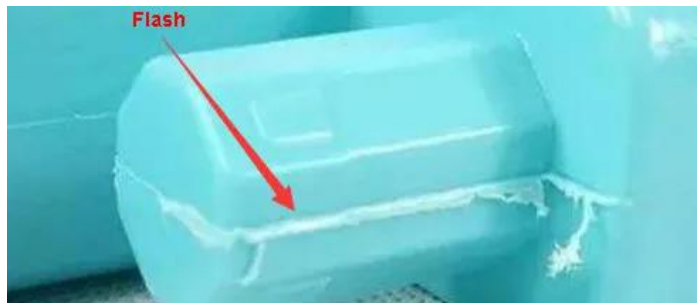

Fig. 12. Flash at the corner of a moulded part [19]

To solve the problem of spall formation, one can [6]:

- reduce the injection speed,

- reduce the temperature of the plasticizing process,

- check the condition of the mold for damage,

- increase the clamping pressure of the mold.

\subsection{Differences in surface texture}

Differences in surface texture are considered a quality defect when they occur despite the uniform surface finish of the injection mold [6].

In order to prevent the discussed quality defect, one should [6]:

- make sure that the mold surface has not been damaged,

- increase the temperature of the plasticizing unit,

- increase the clamping pressure,

- increase or reduce the injection volume.

\subsection{Short molding}

Under-shots (Fig. 13), are material deficiencies usually occurring at locations away from the injection point or where there are thin walls of the product. Typically, underflows are caused by insufficient injection volume, screw valve leakage, or insufficient injection pressure [6].

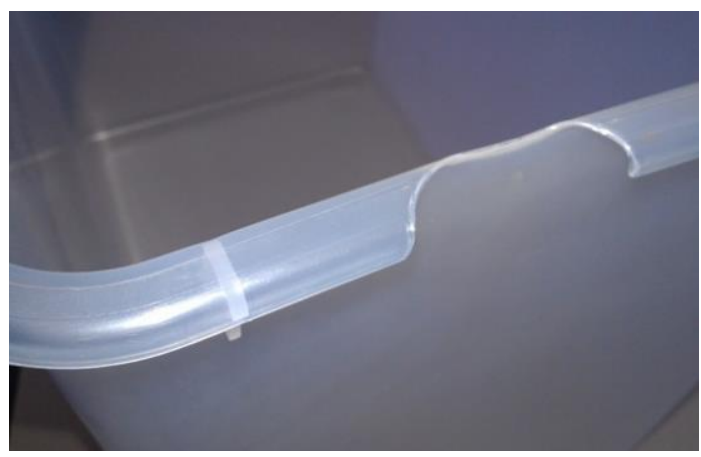

Fig. 13. Short molding at the edge of a molded part [23]

In order to eliminate the possibility of underflow, it is necessary to [6]:

- increase the injection volume, 
- increase the injection speed,

- increase the temperature in the plasticizing unit

- increase the mould temperature, apply reheating of the mould,

- choose a material with lower viscosity,

- increase the injection point size,

- change the position of the injection point.

\subsection{Melt flow marks/streaks}

Plastic flow marks (Fig. 14) are usually caused by too high humidity of the raw material. Most often they occur near the injection point, spreading radially from this place [6].

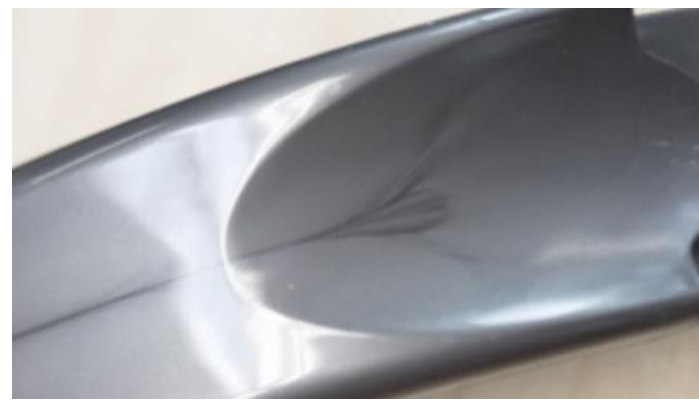

Fig. 14. Melt flow marks on the molding machine [23]

In order to prevent this quality defect, it is necessary to [6]:

- control the moisture content of the raw material,

- dry the raw material and ensure that the influence of external conditions on the plastic is limited,

- reduce the amount of raw material in the tank above the plasticizing unit,

- ensure proper storage conditions of the raw material.

\subsection{Part mass}

The mass of a molded part provide important information about the quality of its manufacturing. Production technology assumes that the mass must be within the limits determined experimentally or at the stage of product design. The exceeding of certain deviations from the acceptable mass indicates a problem with the process and, in effect, a deterioration of the product quality by weakening its structure and strength or other quality defects such as defects, gassings, underflows or overflows [3].

Insufficient product weight may be associated with weakened structure and strength of the product and the occurrence of short molding [3].

Excessive product weight can also be linked to weakening of the structure and strength of the product and to the occurrence of flashes or deformation. Improper mass can be linked to problems such as getting the part stuck in the mould (due to shrinkage) [3].

\section{SUMMARY AND CONCLUSIONS}

The article discusses the issues concerning the production of plastic products with particular emphasis on the injection molding method. The quality defects of products made by this method were discussed. Thanks to the knowledge collected in the literature, solutions eliminating the mentioned quality problems were also proposed. This study allowed us to come up with the following conclusions:

1. Plastics owe their popularity to their low manufacturing costs compared to the materials they replace. They are also characterized by the fact that they can be endowed with properties unattainable by other materials. The advantages of this material are its ease of processing, recovery and wide range of applications.

2. The field of plastic injection molding is extensive. The quality of products manufactured by this method is influenced by many process input factors but also by auxiliary processes (e.g. raw material storage conditions).

3. As with all manufacturing methods, quality defects can occur during the injection molding process of plastic articles resulting in deficiencies or unsatisfactory properties of the molded part.

4. The quality control methods and the features to be controlled for plastic products should be chosen with regard to the technology of a given product, but the most frequent defects described in the literature analysis are characteristic for the production of this type of products. Their occurrence depends on many factors such as the degree of machines and tools exploitation, kind of raw material. It should also be pointed out that they are strongly connected with technological parameters (settings of injection moulding machines) of the process.

5. Expert knowledge accumulated in textbooks and scientific studies summarized in this article allows to make an attempt to eliminate quality defects of moldings. At the same time the mutual dependencies of the process input parameters influencing their occurrence are pointed out. It is worth mentioning the high complexity of the injection molding process, therefore the proposed solutions are of limited use. All factors should be taken into consideration when trying to eliminate the quality defects of the molded parts (injection molding machine settings, type of raw material, raw material storage, mold condition, etc.). 


\section{References}

1. Belcher S. L., 2011, Chapter 16 - Blow Bolding, Applied Plastics Engineering Handbook, William Andrew, Elsevier Inc.

2. Borkowski K., 2015, Plastics industry - materials of the 21st century, Mechanik 04/2015, pp. 278-282, DOI: 10.17814/mechanik.2015.4.158. (in Polish)

3. Chaciński T., 2021, Improvement project of quality control process in production of plastic articles [...], Politechnika Koszalińska. (in Polish)

4. Ebnesajjad S., 2016, Fluoroplastics, William Andrew, Elsevier Inc.

5. Garbacz T., Sikora J. W., 2012, Processing of polymer plastics - laboratory exercises, Politechnika Lubelska. (in Polish)

6. Hague K., iMoulder, Moulding Problems, imtech design. (accessed: January 2021)

7. Hamrol A., 2017, Quality management and engineering, Wydawnictwo Naukowe PWN S.A. (in Polish)

8. Kubiński W., 2008, Manufacturing Engineering and Technology, Wydawnictwa AGH. (in Polish)

9. Kauffer P.H., 2011, Injection molding: Process, design and applications, Nova Science Publishers Inc.

10. Leary M., 2020, Design for Additive Manufacturing, Elsevier Inc.

11. Łunarski J., 2012, Quality management, Wydawnictwo WNT. (in Polish)

12. Mitsoulis E., 2009, Chapter 11 - Calendering of polymers, Advances in Polymer Processing, Woodhead Publishing.

13. Shrivastava A., 2018, Introduction to Plastics Engineering, William Andrew, Elsevier Inc.

14. Svecko R., Kusic D., Kek T., Sarjas A., Hancic A., Grum J., 2013, Acoustic Emission Detection of MacroCracks on Engraving Tool Steel Inserts during the Injection Molding Cycle Using PZT Sensors 2013 13(5), pp. 6365-6479 DOI: 10.3390/s130506365.

15. http://www.anole-hot-runner.com/plastic-injectiontroubleshooting-plastic-black-spots-amp-brownstreaks_379.htm (accessed: August 2021)

16. https://www.appropedia.org/File:Z_calender.png (accessed: August 2021)

17. https://www.beaumontinc.com/injection-moldingglossary/gas-trap/ (accessed: August 2021)

18. https://gudmould.wordpress.com/2019/09/18/weld-linedefect-analysis-and-troubleshooting/ (accessed: August 2021)

19. https://gudmould.wordpress.com/2020/04/08/defectscause-analysis-solutions-for-injection-products/ (accessed: August 2021)

20. http://kits.kitreview.com/fa18cconstreviewdr_3.htm (accessed: August 2021)

21. https://www.milacron.com/pl/produkty/formowaniewtryskowe/w-calosci-elektryczne/elektron/ (accessed: January 2021)

22. https://www.nexpcb.com/blog/how-to-avoid-colorstreaks-and-gloss-difference-in-your-plastic-production (accessed: August 2021)

23. https://www.rapiddirect.com/blog/injection-moldingdefects (accessed: August 2021)

24. http://www.roto-industry.com/ (accessed: August 2021)

25. https://www.worksafe.govt.nz/topic-andindustry/machinery/working-safely-with-plasticproduction-machinery/plastics-extrusion-presses/ (accessed: August 2021)

\section{Biographical notes}

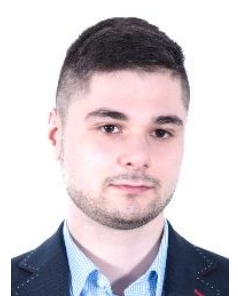

Tomasz Chaciński is currently preparing to defend his Bachelor of Engineering thesis. He is an employee of the Faculty of Mechanical Engineering at the Department of Production Engineering, Technical University of Koszalin. His interests include solving problems in production processes organization, improvement of production systems through automation of their processes and application of dynamic quality control methods.

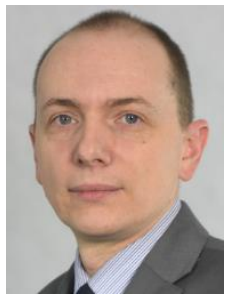

Pawel Sutowski received his $\mathrm{PhD}$ as well as DSc degree in Machinery Construction and Operation from Koszalin University of Technology (Poland), in 2008 and 2020, respectively. Since 2008 he has a didactic-research position in the Department of Production Engineering (Faculty of Mechanical Engineering) at the Koszalin University of Technology, where currently he works as Associate Professor. His scientific work focus on problems concerning quality and efficiency control of machining processes by monitoring and diagnostic output signals. In his work, he uses modern signal acquire and converting unit systems. The most important in his work are non-destructive testing (NDT) methods with the use of acoustic signal and others. He has participated in national research projects, presenting results of his work at international and national conferences. He has published scientific papers in international and national journals, book chapters, as well as conference proceedings. Furthermore, he is also the co-author of one monograph. In his professional work, he was also experience in domestic and foreign industry. 
